Senior Lecturer Florentina Olivia BALU, PhD

E-mail: Florentina.Balu@ unige.ch

University of Geneva

Associate Professor Carmen Valentina RADULESCU, PhD

E-mail: carmen-valentina.radulescu@eam.ase.ro

The Bucharest University of Economic Studies

Associate Professor Dumitru Alexandru BODISLAV, PhD

E-mail: alex.bodislav@ase.ro

Iulian GOLE, PhD Student

E-mail: iuliangole@yahoo.com

Ovidiu Cristian Andrei BUZOIANU, PhD

E-mail: buzoianuovidiu@yahoo.com

Lecturer Sorin BURLACU, PhD

E-mail: sburlacu@amp.ase.ro

Petronela Evelina BALU, PhD Student

E-mail: evelina.balu@yahoo.com

The Bucharest University of Economic Studies

\title{
COST MODELING AND COMPUTATION IN THE HEALTHCARE INDUSTRY. CASE STUDY ON A SWISS MEDICAL CARE ORGANIZATION
}

Abstract. The main objective of this paper is to propose a quasi-analytical method through which we can compute the service costs in healthcare organizations, despite the specificities of various institutions. In building the structure of calculations, the approach is based on quasi-optimal modeling and his application within healthcare institutions; in doing so we focused on organizations specialized in the care of people with disabilities. Generally speaking, the majority of the expenses of these institutions are supported by the state, and, consequently, a control, as well as an evaluation of these costs, is imperatively required. In this context, our paper proposes, tests, and validates an estimation method of the cost of residential care for people with disabilities. This estimation will make it possible to carry out a comparative analysis between the obtained results and the amounts of received subsidies and the pension prices.

Keywords: cost estimation, healthcare organizations, quasi-analytical modeling.

JEL Classification: D 61, M48, I18

DOI: $10.24818 / 18423264 / 55.1 .21 .05$ 
Florentina Olivia Balu, Carmen Valentina Radulescu, Dumitru Al. Bodislav, Iulian Gole, Ovidiu Cristian Andrei Buzoianu, Sorin Burlacu, Petronela Evelina Balu

\section{Literature review}

For a certain times, Swiss healthcare institutions are struggling handling various costs, limitation policies coming from different local, cantonal or federal levels (Curaviva, 2015). Because of this type of territorial administrative organization, there is a large variety regarding the daily cost of care (Federal Statistics Office, 2014). The situation is similar in all kinds of health foundations, regardless of the medical aid specificity. Some researchers discovered the existence of some economies of scale in the medical area (Fillipini,1999) while others (Crivelli et all, 2002) studied the cost efficiency; it was discovered that only $60 \%$ of the nursing homes are closed to the national standard. The appearance of new technologies that may reduce the costs and improve not only the quality of patients' lives but also general working conditions was approached by other researchers (De Veer et al, 2011). The efficiency of using Electronic Medical Record was studied (Hitt \& Tambe, 2016), and the conclusion was unclear: $3 \%$ better results with 2,7\% higher expenditures. The health policy of public authorities aims to streamline the provision of reception services in EMS (medical and social institutions). This streamlining involves setting performance standards for each subsidized facility. To monitor compliance with standards, each institution should define its actual performance (Morard, 2002). The costs of disorders of the brain in what is concerning Switzerland was studied (Maercker et all, 2013) and the results showed that this creates a substantial economic burden for the society therefore trying to create an explicit method of cost explanation seemed to be a natural challenge.

\section{Introduction and research questions}

Generally speaking, a large majority of the charges that healthcare institutions are carrying on (particularly the institutions specialized in the field of mental or physical disability) are supported by the state, and, consequently, control, as well as an evaluation of these costs, are imperatively required to not create premises for exhaustive and unfeasible expenses.

In this context, our paper proposes a method to compute the service costs / residential care cost in healthcare organizations, a tool that can be used in every medical institution.

Our case study and the application of the method are built from data provided by a Swiss healthcare institution specialized in the care of people with disabilities. By the mean of using these data, we proposed, tested, and validated an estimation method of the cost of residential care.

The method is based on a quasi-optimal modeling approach. This estimation will make it possible to develop a comparative analysis between the obtained results regarding the amounts of received subsidies, and the pension prices. 
Cost Modeling and Computation in the Healthcare Industry. Case Study on a Swiss Medical Care Organization

From the beginning, we have to stress out that Switzerland has one of the priciest healthcare systems in the world. Healthcare costs amount is about $12,4 \%$ of the GDP in 2017. Of all the 37 OECD member countries, only the US spends more (17\% GDP), as we can see from the following graphic.

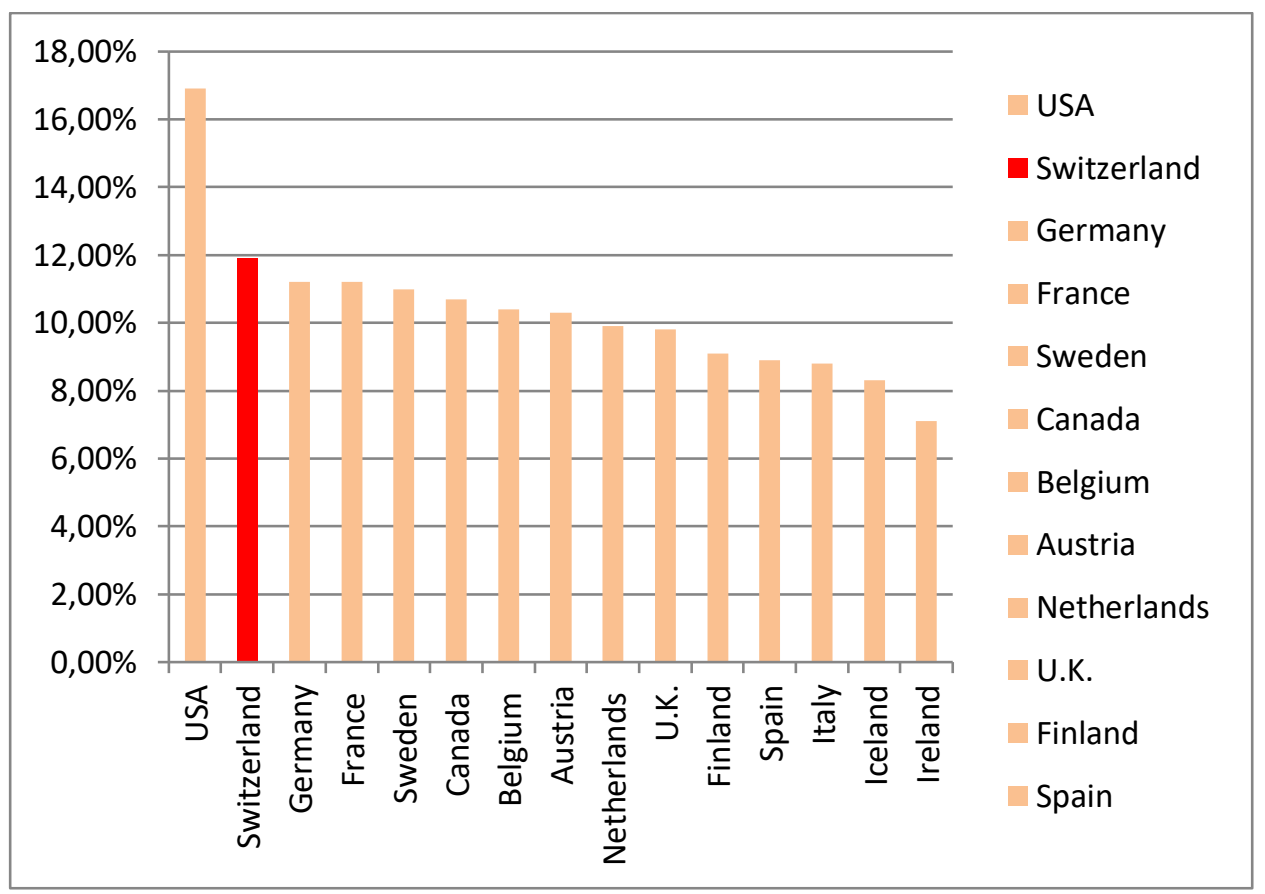

Figure 1. Health expenditure in OECD countries, 2018. Sources: FSO Statistics on health care costs and founding / OECD - Health Statistic 2020

Even though it is generally appreciated as being one of the best worldwide, the Switzerland healthcare system is also very costly, and the financial burden, especially for private households and the cantons, is continuously increasing.

The latest figures show that the total costs of the Swiss healthcare system are comparatively high and that they are rising every year. There are two main reasons to explain the situation: the generally growing economy (if more money is available, more can be spent on health) and the fact that the population is getting older. To that, we may add that new technologies more costly are available in hospitals. In 2018, total expenditure amounted to CHF 81.9 billion ( $\$ 84.4$ billion), an equivalent of costs increasing rate of $2.8 \%$. In the next graphic, we can see the clear steady positive path of cost evolution during years. 
Florentina Olivia Balu, Carmen Valentina Radulescu, Dumitru Al. Bodislav, Iulian Gole, Ovidiu Cristian Andrei Buzoianu, Sorin Burlacu, Petronela Evelina Balu

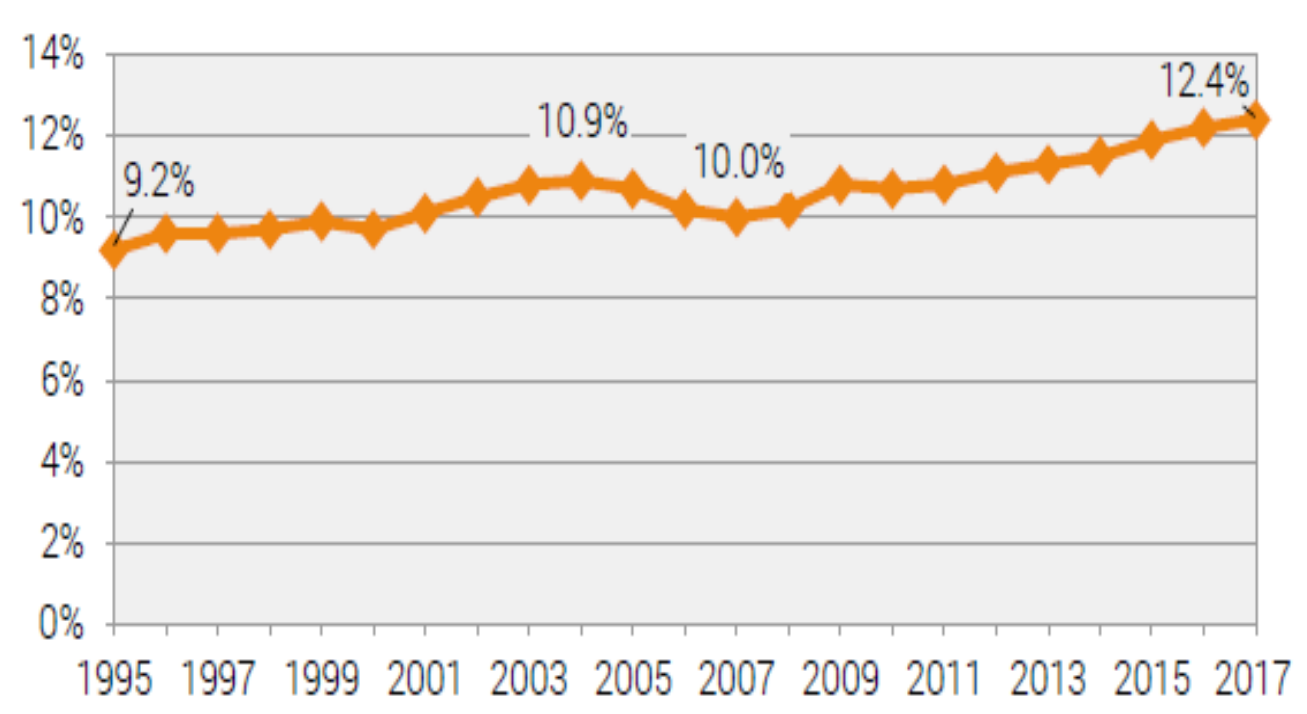

Figure 2. Switzerland's health expenditure in relation to GDP. Source: FSO Statistics on health care costs and funding, FSO 2020.

Overall, the ratio between health expenditure and the gross domestic product (GDP) has increased on average, by $3.2 \%$, between 1995 and 2018 .

In this context, the question of calculating accurately the financial effort that is undertaken for carrying ill people is quite reasonable. As we can see further on, in this paper, we will be focusing on exactly determinate what the costs of residential care for people with disabilities would be.

\section{Current and local context}

Following the consultation, on May 5th, 2015, regarding the draft laws, guidelines and the 2016 - 2020 plan of measures concerning the policy on persons with disabilities, and in the context of the Reform of the financial equalization and the distribution of tasks between the Confederation and the cantons in the field of disability (originally called "Réforme de la péréquation financière et de la répartition des tâches entre la Confédération et les cantons" - known under the acronym of RPT), the specialized institutions targeted by this reform are questioning their financial situation and management of resources.

After the entry into force on January 1st, 2008, of the RPT reform, all responsibilities regarding the planning and financing of homes and workshops for people with disabilities passed from the Confederation to the canton. At the Canton level, the responsibility lies with the Directorate of Health and Social Affairs (Direction de la santé et des affaires sociales - DSAS), Social Security Service (Service de la prévoyance sociale - SPS), which shares with other state entities the 
Cost Modeling and Computation in the Healthcare Industry. Case Study on a Swiss Medical Care Organization

responsibility for implementing the cantonal policy in favor of people with disabilities.

As part of its evaluation mission, the DSAS is also interested in estimating the cost of residential care for people with disabilities. To our knowledge, neither the DSAS nor the specialized institutions have a reliable estimate of the full costs (by structure, by service provided, or per individual) of the care of people with disabilities. In the selected Canton for this research, as well as in all other cantons of the Swiss Confederation, the DSAS applies an old fashioned system of funding for establishments and foundations specializing in the care of people with disabilities. This historic financing system, following the financial equalization between the Confederation and the cantons) must be reviewed.

"The preliminary draft thus gives a comprehensive and coherent picture of the policy relating to the person with a disability and it represents mainly the legal basis for the financial interventions of the State, different from those specified in the legislation on specialized institutions" (DSAS, Explanatory Report on the Preliminary Draft Law on Persons with Disabilities (AP-LPSH) and the Preliminary Draft Law on Specialized Institutions and Occupational Foster Families for Minors (AP LIFAP). Currently, the area of specialized institutions falls exclusively within the area of competence of the state, but the financing of the operating deficit of the institutions is distributed as follows: $45 \%$ by the state and $55 \%$ by the municipalities (communes), as it is explained by different sources as DSAS, Disability Policy, and Action Plan 2016-2020. A new distribution of burdens could therefore be decided as part of the overall project in order to bring more clarity into this real labyrinth of tasks.

In this context, we decided to study what is happening in a specific Swiss foundation, which aims to welcome and support people with mental disabilities by offering them services tailored to their needs. The main question that we are trying to answer is how to estimate the full costs of its residential slots for people in a mental disability situation. This estimation will allow building a comparative analysis between the figures obtained and the amounts of subsidies and pension prices.

Without taking into account at this stage all the specificities inherent to different needs, not necessarily similar, of people being treated in this type of residences, this analysis will also provide a better understanding of the cost structure of each residency / apartment / work shop and will generate an initial estimate of average unit cost per type of service offered by the organization. Of course, the calculation of these costs will require a thorough, dynamic annual analysis, adapted to the evolving needs of people with disabilities.

Based on the cost accounting information provided for the years 2015 and 2016 by the foundation which welcomes and supports people with mental disabilities, this report estimates the full daily unit cost by type of service.

DOI: 10.24818/18423264/55.1.21.05 
Florentina Olivia Balu, Carmen Valentina Radulescu, Dumitru Al. Bodislav, Iulian Gole, Ovidiu Cristian Andrei Buzoianu, Sorin Burlacu, Petronela Evelina Balu

Table 1: Cost fluctuation limits by type of service

\begin{tabular}{||l|l|l|l|l||}
\hline \hline & $\begin{array}{l}\text { Lower } \\
\text { limit }\end{array}$ & $\begin{array}{l}\text { Upper } \\
\text { limit }\end{array}$ & Average 2015 & Average 2016 \\
\hline Residences & 250 & 400 & $375.46 /$ per day & $360.60 /$ per day \\
\hline Apartments & 150 & 200 & $173.98 /$ per day & $165.27 /$ per day \\
\hline $\begin{array}{l}\text { Work- } \\
\text { Shops }\end{array}$ & 20 & 35 & $26.66 /$ per hour & $27.69 /$ per hour \\
\hline \hline
\end{tabular}

The Foundation is aware of the need to implement an advanced cost measurement tool to address the relationship between the needs of the people received, the services provided and the inherent funding, and the need for better allocation of existing resources, while promoting the implementation of innovative care adapted to the evolving needs of the people concerned.

Of course, these financial management considerations in no way will obscure the foundation's recognized excellence in the care provided by the foundation to people with disabilities. This remains the essential mission of the foundation.

\section{Organization of the institution}

We can quickly summarize the nature of the institution analyzed in our research:

- It is a foundation-type structure, semi-public with its cantonal funding for $1 / 2-3 / 4$ of the amount which is divided into cantonal grant and benefits coming from different services (this could be considered as being similar to revenue).

- More specifically, a big part of the patients are staying under medical surveillance in residences and the rest (that still have a certain degree of independence) are living in studios and apartments. There are geographically dispersed work shops where patients are engaged in different activities for different beneficiaries, in order to make them feel useful for society and for the integration purposes.

- Given the fact that foundation is a public fund beneficial, there is an obligation to conduct regular reporting, to justify the use of these funds - The main part of expenses relates to labor, the other part being represented by raw materials, heating, electricity, different supplies. 
Cost Modeling and Computation in the Healthcare Industry. Case Study on a Swiss Medical Care Organization

Table 2 - The components of the structure

\begin{tabular}{||c|l||}
\hline Nr. & \multicolumn{1}{|c|}{ Region / Sector } \\
\hline 1 & Region 1 - Residence 1 \\
\hline 2 & Region 1 - Residence 2 \\
\hline 3 & Region 1 - Residence 3 \\
\hline 4 & Region 1 - Residence 4 \\
\hline 5 & Region 1 - Residence 5 \\
\hline 6 & Region 1 - Residence 6 \\
\hline 7 & Region 1 - Residence 7 \\
\hline \hline 8 & Region 2 - Residence 8 \\
\hline 9 & Region 3 - Residence 9 \\
\hline 10 & Region 4 - Residence 10 \\
\hline \hline 11 & Apartments - Residence 11 \\
\hline 12 & Region 5 - Production, Work shop 1 \\
\hline 13 & Region 6 - Production, Work shop 2 \\
\hline 14 & Occupancy - Work shop 3 \\
\hline
\end{tabular}

From the data point of view, we have quarterly statistics for both benefits, in the number of 14 different types, and expenses by type (the large expenses being wages, as we have previously indicated). 
Florentina Olivia Balu, Carmen Valentina Radulescu, Dumitru Al. Bodislav,

Iulian Gole, Ovidiu Cristian Andrei Buzoianu, Sorin Burlacu, Petronela Evelina Balu

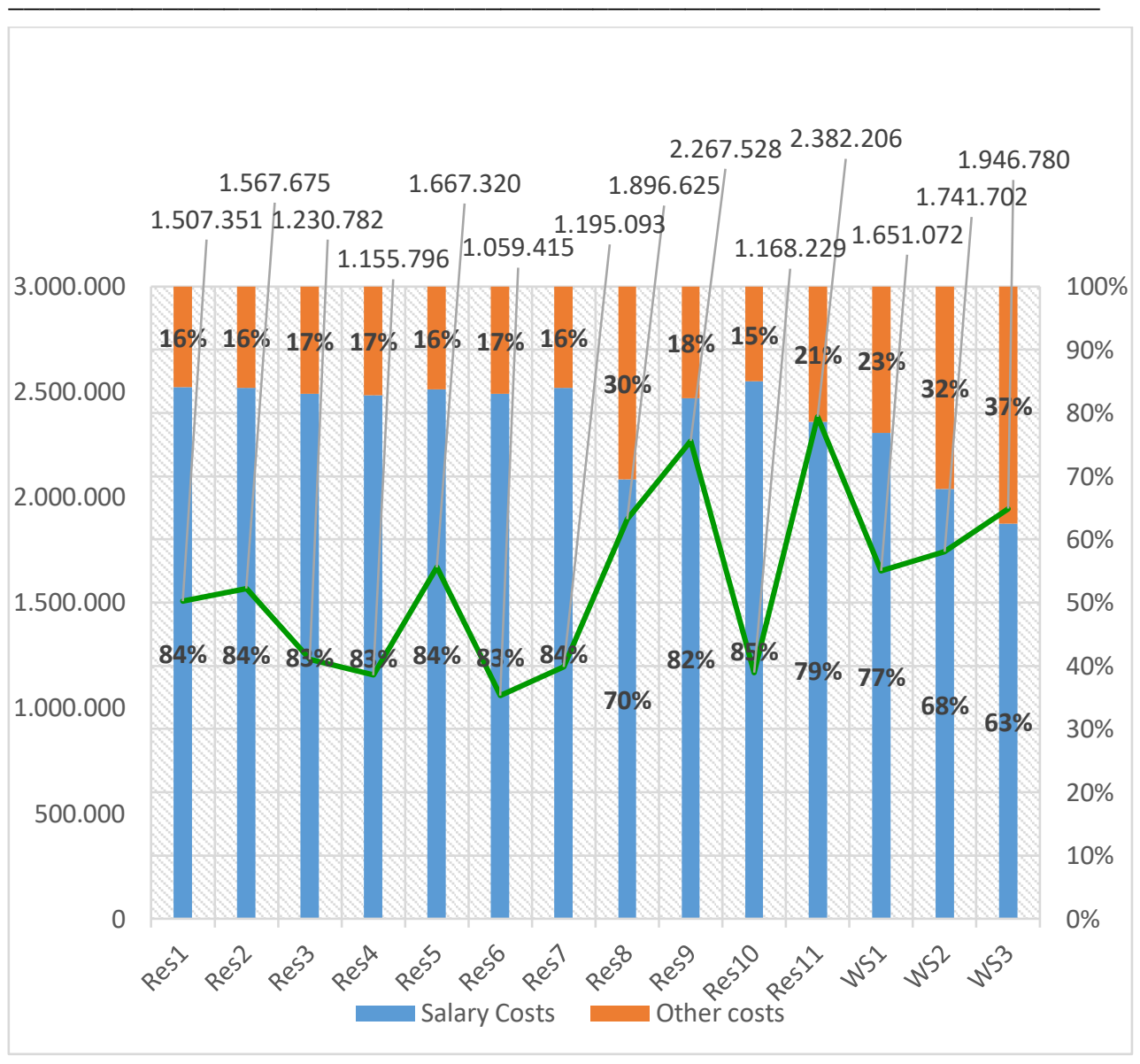

Figure 3 - The structure and volume of charges by residence and work-shops, in 2016.

The problem resulting from this introductory analysis is how to estimate the costs by type of services. 
Cost Modeling and Computation in the Healthcare Industry. Case Study on a Swiss Medical Care Organization

Table 3.1 - Total costs and services (2016, 2017, 8 quarters).

\begin{tabular}{||c|c|c|c|c|c|c|c|c||}
\hline \multirow{3}{*}{ Period } & \multirow{2}{*}{ Costs } & \multicolumn{8}{|c||}{ Region 1 } \\
\cline { 3 - 10 } & & Res 1 & Res 2 & Res 3 & Res 4 & Res 5 & Res 6 & Res 7 \\
\cline { 3 - 10 } & 9 & 9 & 8 & 9 & 9 & 8 & 7 \\
\hline 1 & 5.500 .084 & 777 & 774 & 720 & 764 & 792 & 720 & 656 \\
\hline 2 & 5.533 .725 & 819 & 817 & 728 & 727 & 819 & 728 & 637 \\
\hline 3 & 5.426 .596 & 828 & 799 & 736 & 806 & 813 & 736 & 644 \\
\hline 4 & 5.693 .921 & 827 & 805 & 690 & 828 & 736 & 701 & 659 \\
\hline 1 & 5.524 .957 & 823 & 819 & 694 & 788 & 814 & 672 & 637 \\
\hline 2 & 5.420 .121 & 861 & 812 & 710 & 819 & 809 & 707 & 637 \\
\hline 3 & 5.549 .222 & 920 & 828 & 736 & 777 & 822 & 711 & 644 \\
\hline 4 & 5.943 .274 & 889 & 828 & 736 & 794 & 828 & 644 & 644 \\
\hline Total & 44.591 .901 & 6.744 & 6.482 & 5.750 & 6.303 & 6.433 & 5.619 & 5.158 \\
\hline
\end{tabular}

Table 3.2 - Total costs and services (2016, 2017, 8 quarters).

\begin{tabular}{|c|c|c|c|c|c|c|c|}
\hline \multirow{3}{*}{ Period } & \multirow{2}{*}{$\begin{array}{c}\text { Region } \\
2 \\
\end{array}$} & \multirow{2}{*}{$\begin{array}{c}\text { Region } \\
3 \\
\end{array}$} & \multirow{2}{*}{ Region 4} & \multirow{2}{*}{ Apartments } & \multicolumn{2}{|c|}{ Production } & \multirow{2}{*}{ Occupancy } \\
\hline & & & & & Region 5 & Region 6 & \\
\hline & 20 & 6 & 22 & 32 & 61 & 38 & 38 \\
\hline 1 & 1.665 & 540 & 1.980 & 2.603 & 7.382 & 10.828 & 9.672 \\
\hline 2 & 1.771 & 546 & 2.002 & 2.817 & 16.682 & 10.391 & 9.282 \\
\hline 3 & 1.679 & 552 & 2.024 & 2.826 & 8.503 & 1.526 & 10.296 \\
\hline 4 & 1.810 & 552 & 1.990 & 2.837 & 17.802 & 11.090 & 9.906 \\
\hline 1 & 1.687 & 546 & 2.002 & 2.643 & 17.902 & 11.192 & 10.788 \\
\hline 2 & 1.600 & 511 & 1.984 & 2.652 & 17.954 & 11.185 & 10.653 \\
\hline 3 & 1.790 & 552 & 2.024 & 2.656 & 18.534 & 11.545 & 11.136 \\
\hline 4 & 1.773 & 552 & 2.024 & 2.715 & 18.534 & 11.545 & 11.136 \\
\hline Total & 13.775 & 4.351 & 16.030 & 21.749 & 143.293 & 89.302 & 82.869 \\
\hline
\end{tabular}

Table 4.1 - Salary and services costs (2016, 2017, 8 quarters).

\begin{tabular}{||c|c|c|c|c|c|c|c|c||}
\hline \multirow{2}{*}{ Period } & \multirow{2}{*}{ Costs } & \multicolumn{8}{|c||}{ Region 1 } \\
\cline { 3 - 10 } & & Res 1 & Res 2 & Res 3 & Res 4 & Res 5 & Res 6 & Res 7 \\
\cline { 3 - 10 } & & 9 & 9 & 8 & 9 & 9 & 8 & 7 \\
\hline \hline 1 & 4.209 .634 & 777 & 774 & 720 & 764 & 792 & 720 & 656 \\
\hline 2 & 4.316 .684 & 819 & 817 & 728 & 727 & 819 & 728 & 637 \\
\hline 3 & 4.302 .256 & 828 & 799 & 736 & 806 & 813 & 736 & 644 \\
\hline 4 & 4.445 .534 & 827 & 805 & 690 & 828 & 736 & 701 & 659 \\
\hline 1 & 4.303 .152 & 823 & 819 & 694 & 788 & 814 & 672 & 637 \\
\hline
\end{tabular}

DOI: $10.24818 / 18423264 / 55.1 .21 .05$ 
Florentina Olivia Balu, Carmen Valentina Radulescu, Dumitru Al. Bodislav, Iulian Gole, Ovidiu Cristian Andrei Buzoianu, Sorin Burlacu, Petronela Evelina Balu

\begin{tabular}{||c|r|r|r|r|r|r|r|r||}
\hline 2 & 4.303 .152 & 861 & 812 & 710 & 819 & 809 & 707 & 637 \\
\hline 3 & 4.479 .586 & 920 & 828 & 736 & 777 & 822 & 711 & 644 \\
\hline 4 & 4.479 .586 & 889 & 828 & 736 & 794 & 828 & 644 & 644 \\
\hline Total & 34.839 .583 & 6.744 & 6.482 & 5.750 & 6.303 & 6.433 & 5.619 & 5.158 \\
\hline
\end{tabular}

Table 4.2 - Salary and services costs $(2016,2017,8$ quarters).

\begin{tabular}{|c|c|c|c|c|c|c|c|}
\hline \multirow{3}{*}{ Period } & \multirow{2}{*}{ Region 2} & \multirow{2}{*}{ Region 3} & \multirow{2}{*}{$\begin{array}{c}\text { Region } \\
4\end{array}$} & \multirow{2}{*}{ Apartments } & \multicolumn{2}{|c|}{ Production } & \multirow{2}{*}{ Occupancy } \\
\hline & & & & & Region 5 & Region 6 & \\
\hline & 20 & 6 & 22 & 32 & 61 & 38 & 38 \\
\hline 1 & 1.665 & 540 & 1.980 & 2.603 & 17.382 & 10.828 & 9.672 \\
\hline 2 & 1.771 & 546 & 2.002 & 2.817 & 16.682 & 10.391 & 9.282 \\
\hline 3 & 1.679 & 552 & 2.024 & 2.826 & 18.503 & 11.526 & 10.296 \\
\hline 4 & 1.810 & 552 & 1.990 & 2.837 & 17.802 & 11.090 & 9.906 \\
\hline 1 & 1.687 & 546 & 2.002 & 2.643 & 17.902 & 11.192 & 10.788 \\
\hline 2 & 1.600 & 511 & 1.984 & 2.652 & 17.954 & 11.185 & 10.653 \\
\hline 3 & 1.790 & 552 & 2.024 & 2.656 & 18.534 & 11.545 & 11.136 \\
\hline 4 & 1.773 & 552 & 2.024 & 2.715 & 18.534 & 11.545 & 11.136 \\
\hline Total & 13.775 & 4.351 & 16.030 & 21.749 & 143.293 & 9.302 & 82.869 \\
\hline
\end{tabular}

What differentiates Tables 3.1, 3.2 and 4.1, 4.2 is only about the nature of the costs, the other data remaining identical. It will be noted that we use as services indicators the number of patients admitted and the number of hours realized. If we use potential patients and times we will mechanically reduce costs per benefit because the potential values are consistently higher than the actual values. From our point of view, it is unrealistic to rely on potential unit costs that are not real and generate an optimistic view of costs.

\section{Calculation methodology}

We are using here a quantitative model that is based on the following assumptions:

- The costs and services are observed without error;

- The relationship between costs and delivered services is linear or quasi-linear, so no technological progress during the time interval;

- The standard costs to initialize the model are realistic.

To find the digital solution, we use a quasi-optimal variant of the model, because the number of benefits is greater than the number of periods, so we will say that there is under determination ( 8 periods and 14 benefits). 
Cost Modeling and Computation in the Healthcare Industry. Case Study on a Swiss Medical Care Organization

The general formula of the Quasi-Optimal model

$$
\left[\begin{array}{l}
\min \sum_{i=1}^{n}\left[a_{i}-a_{i}^{*}\right]^{2} \\
S c: \sum_{i=1}^{n} a_{i} x_{i t}=C_{t}, t=1 . . t^{*}
\end{array}\right.
$$

$a_{i}$ - the actual cost of the "i" type benefit;

$a_{i}^{*}$ - the standard cost of the "i" type benefit;

$x_{i t}$ - the quantity / volume of the "i" type benefit during the " $\mathrm{t}$ " period;

$C_{t}$ - the total costs generated by the delivered services of the period "t";

Development of the model and its application on payroll expenses

Step 1: Adapting the model to the Foundation structure -8 periods and 14 benefits

$$
\left[\begin{array}{rl}
\min \sum_{i=1}^{2}\left[a_{i}-a_{i}^{*}\right]=\min \left\{\left(a_{1}-a_{1}^{*}\right)^{2}+\left(a_{2}-a_{2}^{*}\right)^{2}+\ldots \ldots+\left(a_{14}-a_{14}^{*}\right)^{2}\right\} \\
S c_{1}: a_{1} x_{11}+a_{2} x_{21}+\ldots+a_{14} x_{141}=C_{1} \\
S c_{2}: a_{1} x_{12}+a_{2} x_{22}+\ldots+a_{14} x_{142}=C_{2} \\
\\
\quad \ldots \ldots \ldots \ldots \ldots \ldots \ldots \ldots \ldots \ldots \ldots \ldots \ldots \ldots \ldots \ldots \ldots \ldots \ldots \ldots \\
S c_{8}: & a_{1} x_{18}+a_{2} x_{28}+\ldots+a_{14} x_{148}=C_{8}
\end{array}\right.
$$

Step 2: Writing the Lagrange model

$$
\begin{aligned}
\alpha & =\frac{1}{2}\left\{\left(a_{1}-a_{1}^{*}\right)^{2}+\left(a_{2}-a_{2}^{*}\right)^{2}+\ldots . .+\left(a_{14}-a_{14}^{*}\right)^{2}\right\}+\lambda_{1}\left(a_{1} x_{11}+a_{2} x_{21}+\ldots+a_{14} x_{141}-C_{1}\right)+ \\
& +\lambda_{2}\left(a_{1} x_{12}+a_{2} x_{22}+\ldots+a_{14} x_{142}-C_{2}\right)+\ldots \ldots \ldots \ldots . . .+\lambda_{8}\left(a_{1} x_{18}+a_{2} x_{28}+\ldots+a_{14} x_{148}-C_{8}\right)
\end{aligned}
$$

Step 3: Calculations of first degree derivatives

DOI: 10.24818/18423264/55.1.21.05 
Florentina Olivia Balu, Carmen Valentina Radulescu, Dumitru Al. Bodislav,

Iulian Gole, Ovidiu Cristian Andrei Buzoianu, Sorin Burlacu, Petronela Evelina Balu

$$
\left\{\begin{array}{l}
\frac{\partial \alpha}{\partial a_{1}}=a_{1}-a_{1}^{*}+x_{11} \lambda_{1}+x_{12} \lambda_{2}+\ldots+x_{18} \lambda_{8} \\
\frac{\partial \alpha}{\partial a_{2}}=a_{2}-a_{2}^{*}+x_{21} \lambda_{1}+x_{22} \lambda_{2}+\ldots .+x_{28} \lambda_{8} \\
\ldots \\
\frac{\partial \alpha}{\partial a_{14}}=a_{14}-a_{14}^{*}+x_{141} \lambda_{1}+x_{142} \lambda_{2}+\ldots .+x_{148} \lambda_{8} \\
\frac{\partial \alpha}{\partial \lambda_{1}}=a_{1} x_{11}+a_{2} x_{21}+\ldots+a_{14} x_{141}-C_{1} \\
\frac{\partial \alpha}{\partial \lambda_{2}}=a_{1} x_{12}+a_{2} x_{22}+\ldots+a_{14} x_{142}-C_{2} \\
\cdots \\
\frac{\partial \alpha}{\partial \lambda_{8}}=a_{1} x_{18}+a_{2} x_{28}+\ldots+a_{14} x_{148}-C_{8}
\end{array}\right.
$$

Step 4: Conversion into a system of 22 equations with 22 variables $(8+14)$

$$
\left\{\begin{array}{l}
a_{1}-a_{1}^{*}+x_{11} \lambda_{1}+x_{12} \lambda_{2}+\ldots .+x_{18} \lambda_{8}=0 \\
a_{2}-a_{2}^{*}+x_{21} \lambda_{1}+x_{22} \lambda_{2}+\ldots .+x_{28} \lambda_{8}=0 \\
\ldots \\
a_{14}-a_{14}^{*}+x_{141} \lambda_{1}+x_{142} \lambda_{2}+\ldots .+x_{148} \lambda_{8}=0 \\
a_{1} x_{11}+a_{2} x_{21}+\ldots+a_{14} x_{141}-C_{1}=0 \\
a_{1} x_{12}+a_{2} x_{22}+\ldots+a_{14} x_{142}-C_{2}=0 \\
\ldots \\
a_{1} x_{18}+a_{2} x_{28}+\ldots+a_{14} x_{148}-C_{8}=0
\end{array}\right.
$$

Step 5: Writing the above mathematical system in matrix form: 
Cost Modeling and Computation in the Healthcare Industry. Case Study on a Swiss Medical Care Organization

$$
\left(\begin{array}{cccccccc}
1 & 0 & \ldots & 0 & x_{11} & x_{12} & \ldots & x_{18} \\
0 & 1 & \ldots & 0 & x_{21} & x_{22} & \ldots & x_{28} \\
\ldots & \ldots & \ldots & \ldots & \ldots & \ldots & \ldots & \ldots \\
0 & 0 & \ldots & 1 & x_{141} & x_{142} & \ldots & x_{148} \\
x_{11} & x_{21} & \ldots & x_{141} & 0 & 0 & \ldots & 0 \\
x_{12} & x_{22} & \ldots & x_{142} & 0 & 0 & \ldots & 0 \\
\ldots & \ldots & \ldots & \ldots & \ldots & \ldots & \ldots & \ldots \\
x_{18} & x_{28} & \ldots & x_{148} & 0 & 0 & \ldots & 0
\end{array}\right) \cdot\left(\begin{array}{c}
a_{1} \\
a_{2} \\
\\
a_{14} \\
\lambda_{1} \\
\lambda_{2} \\
\ldots \\
\lambda_{8}
\end{array}\right)=\left(\begin{array}{c}
a_{1}^{*} \\
a_{2}^{*} \\
\\
a_{14}^{*} \\
C_{1} \\
C_{2} \\
\ldots \\
C_{8}
\end{array}\right)
$$

Step 6: The calculation of the solution of this matrix system:

$$
\left(\begin{array}{c}
a_{1} \\
a_{2} \\
a_{14} \\
\lambda_{1} \\
\lambda_{2} \\
\ldots \\
\lambda_{8}
\end{array}\right)=\left(\begin{array}{cccccccc}
1 & 0 & \ldots & 0 & x_{11} & x_{12} & \ldots & x_{18} \\
0 & 1 & \ldots & 0 & x_{21} & x_{22} & \ldots & x_{28} \\
\ldots & \ldots & \ldots & \ldots & \ldots & \ldots & \ldots & \ldots \\
0 & 0 & \ldots & 1 & x_{141} & x_{142} & \ldots & x_{148} \\
x_{11} & x_{21} & \ldots & x_{141} & 0 & 0 & \ldots & 0 \\
x_{12} & x_{22} & \ldots & x_{142} & 0 & 0 & \ldots & 0 \\
\ldots & \ldots & \ldots & \ldots & \ldots & \ldots & \ldots & \ldots \\
x_{18} & x_{28} & \ldots & x_{148} & 0 & 0 & \ldots & 0
\end{array}\right)^{-1} \cdot\left(\begin{array}{c}
a_{1}^{*} \\
a_{2}^{*} \\
\\
a_{14}^{*} \\
C_{1} \\
C_{2} \\
\ldots \\
C_{8}
\end{array}\right)
$$

\section{Results and interpretation}

As can be seen in Tables 5 and 6 , the errors per period are modest when compared to the financial amounts. If we have a closer look at these errors over the whole interval and cumulatively, they are very close to zero.

The application of the model on payroll expenses

Table 5 - Unit costs by services and type of costs

\begin{tabular}{||c|c|l|r|l||}
\hline \hline Nr. & Regions / Residence & Total costs & Payroll costs & $\begin{array}{l}\text { Other } \\
\text { costs }\end{array}$ \\
\hline 1 & Region 1 - Residence 1 & 360.9023063 & 281.5145128 & 79.3877934 \\
\hline 2 & Region 1 - Residence 2 & 360.8671271 & 281.4867554 & 79.3803717 \\
\hline 3 & Region 1 - Residence 3 & 360.7691837 & 281.4092039 & 79.3599798 \\
\hline 4 & Region 1 - Residence 4 & 360.8431764 & 281.4677913 & 79.3753851 \\
\hline 5 & Region 1 - Residence 5 & 360.8605708 & 281.4815641 & 79.3790066 \\
\hline 6 & Region 1 - Residence 6 & 360.7516556 & 281.3953252 & 79.3563304 \\
\hline 7 & Region 1 - Residence 7 & 360.6899726 & 281.3464847 & 79.3434879 \\
\hline
\end{tabular}

DOI: 10.24818/18423264/55.1.21.05 
Florentina Olivia Balu, Carmen Valentina Radulescu, Dumitru Al. Bodislav, Iulian Gole, Ovidiu Cristian Andrei Buzoianu, Sorin Burlacu, Petronela Evelina Balu

\begin{tabular}{|c|c|c|c|c|}
\hline 8 & Region 2 - Residence 8 & 361.8429485 & 282.2594098 & 79.5835387 \\
\hline 9 & Region 3 - Residence 9 & 360.5819940 & 281.2609873 & 79.3210067 \\
\hline 10 & Region 4 - Residence 10 & 362.1446730 & 282.4983149 & 79.6463581 \\
\hline 11 & Apartments - Residence 11 & 167.9099868 & 131.0042002 & 36.9057866 \\
\hline 12 & $\begin{array}{l}\text { Region } 5 \text { - Production } \\
\text { work shop } 1\end{array}$ & 46.1728081 & 36.2416290 & 9.9311791 \\
\hline 13 & $\begin{array}{l}\text { Region } 6 \text { - Production } \\
\text { work shop } 2\end{array}$ & 38.9488135 & 30.5213767 & 8.4274368 \\
\hline 14 & Occupancy - work shop 3 & 38.0880625 & 29.8398826 & 8.2481800 \\
\hline
\end{tabular}

Table 6 - Estimated percentage of error per period

\begin{tabular}{|l|c|c|}
\hline & Error concerning total costs / period & Error concerning salary costs \\
\hline 1 & $-1,43195376$ & 0,616991501 \\
\hline 2 & $-1,196127227$ & $-1,049276355$ \\
\hline 3 & 4,009707948 & 2,501687007 \\
\hline 4 & $-2,087417167$ & $-2,020807052$ \\
\hline 5 & 0,321465767 & 0,638119658 \\
\hline 6 & 2,019211054 & 0,39951614 \\
\hline 7 & 3,030740877 & $-0,278460074$ \\
\hline 8 & $-4,192517332$ & $-0,684206904$ \\
\hline
\end{tabular}

We could split the sample into two 4-period intervals. However, only period 8 marks a variation of $7 \%$ compared to the previous one, which is a little atypical. If we calculate the 2015 and 2016 averages, the difference is $1.278519 \%$. For the completed period of 2017 , it will be necessary to verify that this peak of period 4 for 2016 was a temporary anomaly. If by chance the 2017 situation should show a trend, then the period 2015 should be deleted and replaced by 2017 by re-making the estimates. 
Cost Modeling and Computation in the Healthcare Industry. Case Study on a Swiss Medical Care Organization

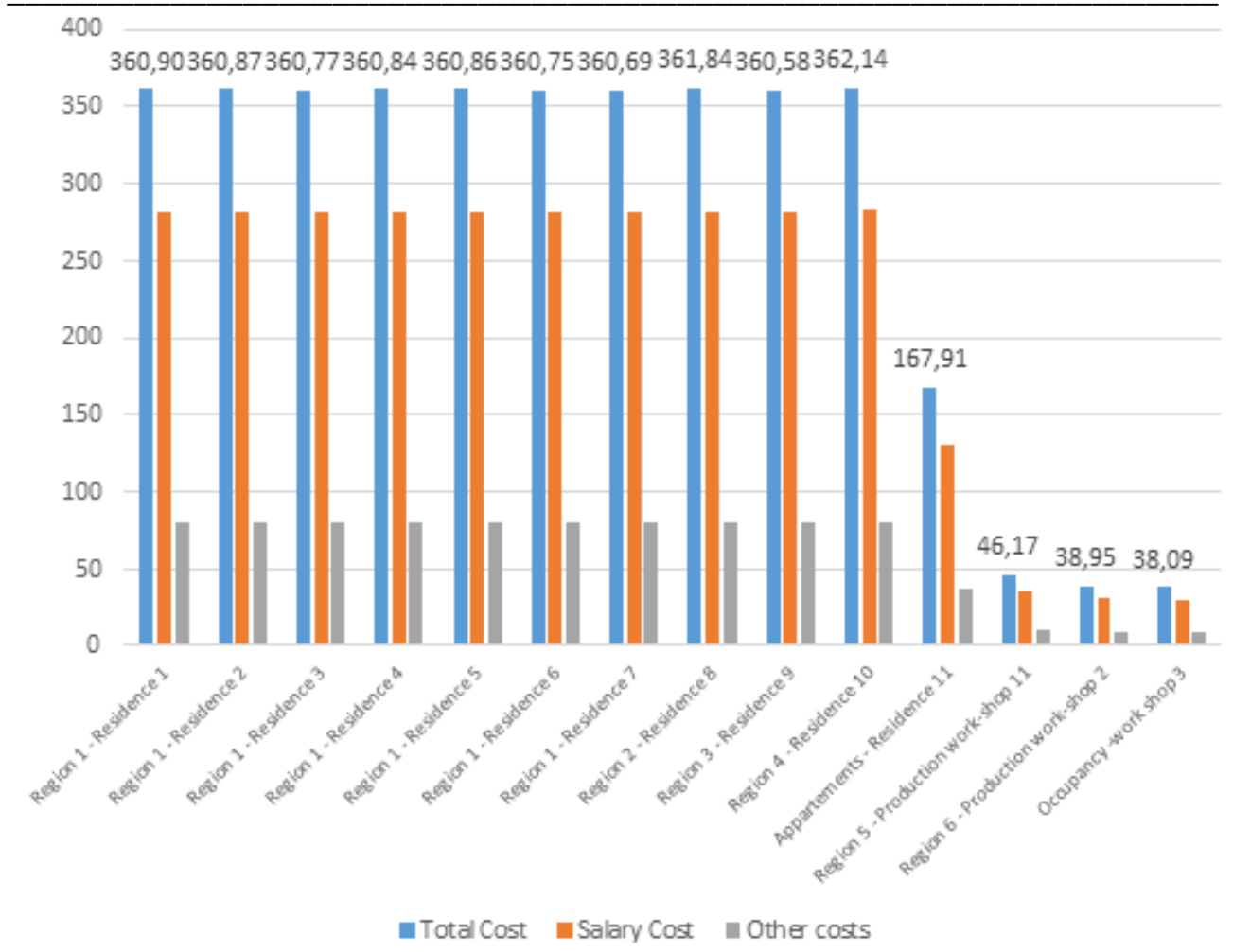

Figure 4 - Effective daily cost by service and type of expense (in CHF)

As was stated in the previous analysis, from the graphic above we can visualize the fact that the values of total costs remain high in all residencies except for the apartments where people need less medical care. We could also see that the costs of integrating patients in work-shops are low, therefore this activity should continue. Overall, wage costs account for most of the total costs.

\section{Conclusions}

In summary, the values of the real unit cost by type of service (residences and work-shops) and type of costs (salaries and other expenses), presented in the graph above, show a detailed reality regarding cost sizes.

These costs show approximately equal values for residences regardless of their location, but much higher than the costs per apartment. As for the costs of the work-shops, as it could have anticipated, they are much lower than the costs of the residences and apartments.

In practice, the "quasi-optimal" approach and the application of this modeling remain however very difficult because the institutions of this sector of activity do not have complete and well-structured financial data and personnel specialized in financial analysis. Also, there is a lack of preoccupation for resource planning. The situation could be rectified by specific courses taken by those dealing with the accounting records of the company.

DOI: 10.24818/18423264/55.1.21.05 
Florentina Olivia Balu, Carmen Valentina Radulescu, Dumitru Al. Bodislav, Iulian Gole, Ovidiu Cristian Andrei Buzoianu, Sorin Burlacu, Petronela Evelina Balu

The quasi-optimal model proposed could be used by all medical institutions in order to give clear explanations about how cantonal financial resources are spent. Even though the end results are not different compared with traditional method (historical prices), at least now there is a clear justification of financial resources needed by health institutions in order to treat correctly their patients.

\section{REFERENCES}

[1] Aymard-Martinot, N., Swinarski, Z., H. \& Morard, B. (2002), Balanced Scorecard: Evaluation de la performance dans un établissement médico-social. Retrieved from https://archive-ouverte.unige.ch/unige:5826;

[2] Crivelli L, Filippini M, Lunati D. (2002), Regulation, Ownership and Efficiency in the Swiss Nursing Home Industry. Int J Health Care Finance Econ. 2002;2:79-97. Kluwer Academic Publishers. The Netherlands;

[3] Curaviva Herausforderungen und Erfolgsfaktoren für Altersinstitutionen in naher Zukunft Online-Umfrage im Jahr 2009 und 2015 im Auftrag von CURAVIVA Schweiz. 2015. Retrieved from

https://www.curaviva.ch/files/Z3FVMN3/herausforderungen und erfolgsfaktoren fue $\underline{\text { r_altersinstitutionen_in_naher_zukunft__studie_curaviva_schweiz_qualis_evaluatio }}$ n_2015.pdf;

[4] De Veer, A., Fleuren, M, Bekkema N. \& Francke A. (2011), Successful Implementation of New Technologies in Nursing Care: A Questionnaire Survey of Nurse-Users. MC Med Inform Decis Mak. 2011;11:67. doi: 10.1186/1472-6947-11-67; [5] Direction de la santé et des affaires sociales DSAS, RAPPORT EXPLICATIF relatif à l'avant-projetde loi sur la personne en situation de handicap (AP-LPSH) et l'avant-projet de loi sur les institutions spécialisées et les familles d'accueilprofessionnellespour mineur-e (AP-LIFAP). Retrieved from https://www.fr.ch/sites/default/files/contens/cha/_www/files/pdf74/fr_RAP_RPT.pdf; [6] Federal Statistics Office (2014), Indicators for Swiss Nursing Homes. Retrieved from

https://www.bfs.admin.ch/bfs/fr/home/statistiques/sante/cout-financement.html;

[7] Fillipini, M. (1999), Economies of Scale in the Swiss Nursing Home Industry. Department of Economics - Università della Svizzera Italiana. Retrieved from www.econ.uzh.ch/static/wp_soi/wp9901.pdf;

[8] FSO - Statistics on Health Care Costs and Founding / OECD - Health Statistic 2020. Retrieved from

https://www.bfs.admin.ch/bfs/en/home/statistics/health/costsfinancing.assetdetail.12567547.html;

[9] Hitt, L. \& Tambe, P. (2016), Health Care Information Technology, Work Organization, and Nursing Home Performance. ILR Review. 2016;69(4):834-59; [10] Maercker, A., Perkonigg, A., Preisig, M., Schaller, K. \& Weller, M. (2013), The Costs of Disorders of the Brain in Switzerland: An Update from the European Brain Council Study for 2010. Swiss Medical Weekly, 143:online. Retrieved from https://doi.org/10.4414/smw.2013.13751. 